\author{
С.В. Борзых
}

\title{
СИНДРОМ ЭЛЕКТРОНИКА
}

\begin{abstract}
Аннотация. Объектом исследования является некоторая косность человеческого мышления, обусловленная его пребыванием в рамках каких-то конкретных обстоятельств, культуры, эпохи. Особое внимание уделяется тому, как именно мы смотрим на мир, что в нём замечаем и как это для себя и окружающих объясняем. Последовательно рассматриваются все отмеченные составляющие компендиума факторов, влияющих, на наш взгляд, на мир, которые не могут быть отброшены ни одним индивидом, включая и любого учёного. Главными методами исследования служат позаимствованные из медицины принципы диагностики взаимосвязанных симптомов с последующим выведением синдрома.

Основным выводом проведённого исследования выступает зависимость нашего мышления от тех обстоятельств, в которых мы все пребываем. Новизна проявляется в том, что был использован аппарат, несвойственный для подобного рода выводов. Предполагается, что мы склонны решать поставленные перед нами задачи теми методами, которые нам удобны, но не которые оптимальны для этого.
\end{abstract}

Ключевые слова: синдром, мышление, эпоха, обстоятельство, культура, понимание, объяснение, решение, разум, мировоззрение.

Abstract. The object of the research is some rigidity of human thinking as a result of particular circumstances, cultural environment and epoch. Special attention is paid to the way we see this world, what we observe there and how we explain observed phenomena to ourselves and other people. The author of the article successively analyze all the factors that influence our world view and can't be ignored by anyone including a researcher. As the main research methods, the author apply medical principles of diagnostics of interrelated symtpoms and syndromic analysis. The main conclusion of the research is that there is a certain dependence between our way of thinking and particular circumstances we live in. The novelty of the research is caused by the fact that the author has used the methods and techniques that are not typical for making such conclusions. The author also assumes that we tend to solve our tasks by using methods that are convenient yet nto always beneficial.

Key words: solution, explanation, understanding, culture, circumstance, epoch, thinking, syndrom, mind, world view.

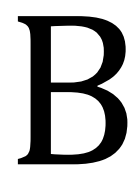

относительно старом советском фильме «Приключения Электроника» был такой эпизод. Сыроежкину и его одноклассникам дали задание по математике. Один из главных героев, будучи не особо усидчив, передаёт это бремя роботу, которого он не так давно встретил, и тот с ним успешно справляется. Проблема, однако, состоит в том, что, несмотря на правильность ответа, сама процедура, с помощью которой он был найден, предполагает применение крайне сложного, по крайней мере, для уровня знаний того школьника, аппарата. И, разумеется, упражнения можно было сделать, используя куда более простые алгебраические операции.

Всё это можно назвать склонностью усложнять себе жизнь там и тогда, где и когда можно обойтись более простыми механизмами решения поставленных задач. Тот факт, что создателем Электроника был профессор, говорит о том, что последний, надо полагать, был знаком не только с арифметикой, но и вообще с целым комплексом математических теорий и построений, применение которых для него было делом обычным, если не тривиальным, а потому он и заложил их в робота.

По сути - отвлекаясь, конечно, от замысла самого фильма - тут можно говорить о том, что это профессор, а вовсе не Электроник решал задачу, приготовленную учителем для Сыроежника и его одноклассников. И сделал он это так, как поступил бы любой на его месте, по крайней мере так, как её бы выполнил всякий, если так позволительно выразиться, профессиональный математик. И тут как раз и кроется то, о чём будет вестись речь в данной статье.

Несмотря на то, что в науке работает принцип экономии, а также тесно связанная с ним бритва Оккама, в действительности учёные, но ещё больше обыватели нередко обращаются не к самым простым способам решения проблем, которые нередко имеются, хотя и не замечаются, но сильно усложняют себе жизнь, применяя более комплексные их аналоги. И это касается не только сугубо математических упражнений и даже не обязательно формул и законов, но и вообще всей нашей жизни. Что это значит? 


\section{Психология и психотехника 3(90) • 2016}

Есть огромный смысл в том, чтобы взглянуть на многие, если не все, наши воззрения и оценки, а также механизмы, используемые нами в процессе устранения возникающих перед нами проблем, с позиции именно Сыроежкина и его учителя, но не Электроника и его создателя. Понятно, что решить ту или иную задачу можно разными способами, но в том-то и дело, что порой более простые из них куда более предпочтительны, а, главное, менее затратны и неповоротливы, чем их сложные аналоги.

Всё это заставляет говорить о наличии - вслед за несколько простоватым и бросающимся в глаза именем робота - y, по крайней мере, современных людей синдрома Электроника, заключающийся в том, чтобы излишне усложнять ситуацию, применяя и используя где надо и где нет слишком комплексные и далеко не очевидные способы решения задач, подходы и оценки, несмотря на наличие альтернатив. Поэтому здесь мы попытаемся показать, что данный синдром присущ всем нам, и что он нередко становится причиной многих проблем, к которым он затем нередко применяется, только усугубляя наше положение. Однако главный упор мы всё же сделаем на групповые представления просто потому, что они наиболее ярко высвечивают особенности функционирования как самого синдрома, так и принципов его воплощения в жизнь.

Прежде всего, необходимо отметить следующее. Называть что-либо синдромом всегда опасно. И даже не потому, что мнительные люди обязательно заметят его признаки у себя, как это сделал персонаж Джерома К. Джерома в «Трое в лодке, не считая собаки» [1], а потому, что не всё так может быть обозначено. Статья на сетевом портале Академик [2] говорит о том, что так обозначают ряд симптомов, имеющих общее происхождение и свидетельствующих о наличии некоторого заболевания или просто проблемы. Разумеется, здесь мы не преследуем цели описать именно недуг, но, скорее, стремимся к тому, чтобы показать, как наши представления ограничивают нас.

Как и в случае с медицинскими хворями, синдром Электроника состоит из нескольких симптомов, которые мы теперь и опишем. В качестве первого выступает наличие у человека и, соответственно, группы людей некоторых воззрений. Может показаться, что тут мы говорим о банальности разумеется, всякий индивид или их коллектив неизбежно имеют какие-то представления или широкий их круг, касающийся самых разнообразных вещей и явлений. Всё это так. Но из данного утверждения следует несколько весьма нетривиальных выводов, которые, однако, редко вообще принимаются в расчёт.
Во-первых, если некто имеет определённые воззрения, то это автоматически означает, что у него отсутствуют другие. Если, скажем, вы владеете русским языком, то, скорее всего, не знаете всех прочих. Проблема состоит в том, что мы все содержим в своей голове лишь крохотную часть действительности, которую, вместе с тем, расширяем до уровня целого. Достаточно посетить любой диспут для того чтобы понять, насколько часто люди забывают о том, что их опыт и знания принадлежат исключительно им и не являются достоянием всех остальных, и более того по определению индивидуальны и глубоко личностны. Отчасти это может быть объяснено с помощью понятия субъективности, но для наших целей оно неполно. То или иное сообщество всегда и всюду владеет только небольшим сегментом информации о мире - все другие ему, как правило, неизвестны.

Это можно продемонстрировать следующими рассуждениями И. Морриса, хотя он и применяет подобный подход в отношении исторической летописи [3, р. 9]. Априори любое наше знание не только временно, но и неполно. В этой связи он приводит пример восьмитомной биографии У. Черчилля. Несмотря на весь этот колоссальный объём, должно быть понятно, что всего об этом политике и общественном деятеле мы даже на стольких страницах написать не получится. Всегда что-то останется за кадром. Можно выразить это иначе: самое лучшее описание мира - это он сам, но по очевидным причинам такой ответ для нас неудовлетворителен.

Как бы то ни было, но здесь для нас важно то, что какими бы многосторонними и всеобъемлющими ни были наши представления о реальности, они с неизбежностью окажутся неполными и частичными. Поэтому мы и имеем право говорить о том, что наличие любых знаний также предполагает отсутствие всех остальных, что только усугубляется нашей склонностью считать себя правыми, несмотря даже, или вопреки, свидетельствам обратного.

Во-вторых, любые воззрения имеют свою летопись, которая, разумеется, не похожа на все прочие нарративы. События уникальны, они не затрагивают всех в равной степени и не влияют на нас одинаково. Одно и то же происшествие оставит разные следы. Если мы суммируем все отдельные случаи в некоторую цепочку, то получим именно историю, которую нельзя будет отождествить с любой иной. У групп людей, как и у индивидов, также имеются свои хроники, опять же несводимые к остальным. Как бы то ни было, но данный факт также нередко упускается, однако, как нетрудно заметить, он име- 


\section{Потенциал интеллекта}

ет далеко идущие последствия, суть которых можно подытожить констатацией наличия различного взгляда на мир.

И это касается не только отдельных обществ или культур, но присуще в том числе и науке. Нетрудно найти примеры, когда по-настоящему прорывные исследования и гениальные открытия оказывались невостребованными и ненужными современникам только потому, что не укладывались в наличную и поддерживаемую всеми парадигму. Скажем, Г. Мендель так и умер в безвестности и был понят значительно позже, и то же самое можно сказать в отношении, увы, очень многих учёных.

Любая жизнь по определению зависит от того пути, который она преодолела, вообще это следует из самой теории эволюции [4]. У всех нас есть прошлое, и без него мы бы не были там и теми, где и какими мы являемся в реальности. Учитывая тот факт, что истории у нас всех разные, не должно удивлять то, что и на мир мы смотрим непохожим друг на друга образом, а также, естественно, оцениваем его и что-то думаем по поводу него также по-своему.

В-третьих, люди не похожи друг на друга не только своими историями или опытом, но и сугубо физиологически. Все мы имеем разные носы, губы, желудки, пищеводы, что объективно заставляет нас смотреть на мир по-особенному, хотя, конечно, и не стоит заходить в подобных утверждениях слишком далеко

Если, скажем, кому-либо слышатся голоса в силу некоторых функциональных повреждений головного мозга, то он будет вынужден как-то с ними взаимодействовать, что, естественно, принудит его быть другим. Вообще человек склонен не замечать того, что, например, его внешность во многом формирует его круг общения. Но то же самое касается и всего остального строения организма и его уникальных черт. В случае же с обществом мы можем указать на понятие фенотипа, нисколько не намереваясь скатываться в область оценочных категорий и, уж тем более, френологии. Действительно, окружающая нас среда, равно как и наше воздействие на неё и на наших близких, а также далёких нам людей отчасти повинны в том, как мы глядим на них и на себя.

Тут крайне полезным будет взгляд на пол, но не вниз, а на разницу между мужчинами и женщинами. Как на обывательском, так и на научном уровнях давно известно, что воспринимаем мы мир далеко не одинаково. И это как раз и связано с тем, что тела наши устроены, пусть и в масштабах животного мира не сильно, но внутри нашего собственного вида несхожим образом, что отчасти и предопределяет расхождение взглядов между нами.

В-четвёртых, мы все проживаем в разные эпохи. Можно долго изгаляться над тем, что в прошлом звучало бы дико, тогда как сегодня воспринимается как само собой разумеющееся. Однако всё это верно. Мы имеем то, чем не обладали наши предки, и у нас отсутствует то, что у них, напротив, было в наличии. Отдельные предметы и явления кардинально меняют жизнь, что, например, справедливо в отношении высоких технологий, но и менее явные, однако всё же значительные черты современности - для каждого свои - вносят поправки в наш взгляд на мир. Трудно, если вообще осуществимо, отказаться от реакции на то, что нас окружает, поэтому, даже при тотальном нежелании контактировать со всем новым, мы вынуждены как-то ко всему этому относиться.

Особенно заметно влияние на нас эпохи в случае с информационными технологиями. Сегодня, например, стало обыденностью размещать в тех или иных социальных сетях информацию о себе, о своих близких, о своих пристрастиях, о, наконец, той пищи, которую вы поглощаете. Но в том-то и дело, что они возникли - эти строки пишутся в 2016-ом году - всего лишь десять лет, да и то не все и не сразу. Однако эффект, ими произведённый, поистине невероятен. Меньше чем за декаду мы кардинально изменили свои привычки, а вместе с ними и наши воззрения, в том числе о том, что нормально, а что - нет.

И это касается не только и даже не столько нашего времени, но и вообще любого предшествовавшего ему и не обязательно как-то связано с великими открытиями или изобретениями, хотя последние явно обостряют нашу реакцию. В любом случае надо понимать, что мы все укоренены в той эпохе, которой и принадлежим, а это, в свою очередь, заставляет нас смотреть на мир строго определённым ею способом.

И, наконец, в-пятых. Мы все имеем привычку воспринимать свои воззрения как естественные, тогда как они таковыми могут и не являться, а зачастую вообще представляют собой противоположность этому. Например, кто-то может утверждать, что Родина, спорт или что бы то ни было ещё это главное, только на том основании, что он так считает. Конечно, в данном случае вы непременно услышите большое количество «доказательств», которые, однако, будут зиждиться исключительно на субъективности и выводиться из следствия, но не из причины. Мы настолько, если так можно выразиться, погрязли в самих себе, что порой нам бывает крайне тяжело освободиться или хотя бы 


\section{Психология и психотехника 3(90) • 2016}

задуматься о своей искусственности, о том, насколько мы на самом деле случайны, а не детерминированы. Общества также страдают от подобных напастей, что делает наш аргумент релевантным, разумеется, и в их отношении.

Кроме того, за последние несколько десятков лет исследователями были выявлены многочисленные склонности и предрасположенности, которыми страдает всякий из нас даже вне зависимости от того, знает она или он об их существовании или же нет [5]. Проблема усугубляется тем, что обычный человек, а, значит, и их совокупности, попросту не ведает о том, что регулярно совершает огромное количество ошибок, связанных преимущественно с тем, как устроен наш организм. Принимая во внимание, что таких людей большинство, не приходится удивляться тому, что и общество тоже таково.

Ситуация обостряется тем, что мы привыкли делить весь мир - социальный, разумеется - на свой и чужой. Выражаясь иначе, мы думаем, что есть мы и какие-то они. Вторые, естественно, хуже нас, именно они заблуждаются, и только им и свойственна субъективность. Мы же, напротив, лучше, почти не ошибаемся и объективны настолько, насколько это в принципе возможно. Учитывая то, что на прошлое порой смотрят с некоторой долей снисхождения, получается гремучая смесь высокомерия и зазнайства.

В принципе, мы не сказали ничего нового. Люди и их группы имеют мировоззрения, которые, с одной стороны, формируются своими создателями, а, с другой стороны, влияют на своих носителей. Именно на последнее обстоятельство и необходимо обратить особое внимание. Таким образом, первый симптом сводится к простому наличию у человека или общества некоторой совокупности представлений о мире и обо всём том, что в нём случается или может произойти.

Второй симптом, в общем и целом, вытекает из первого. Проблема большинства людей состоит в том, что любую задачу они стремятся решить в рамках знакомой и привычной им системы координат. В действительности мы все очень редко, если вообще когда-либо, ставим себя на место другого. В отношении эмоциональных переживаний такой подход отчасти работает, тем более, что, как полагают некоторые учёные, этот механизм основан на зеркальных нейронах, которые мы попросту не контролируем [6]. Мы чувствуем эмпатию, что позволяет нам сопереживать окружающим и делает нас более восприимчивыми, но в то же время её возможности крайне ограничены и, как правило, распространяются только на ближний круг инди- вида. Ничего даже отдалённо похожего на эмпатию в интеллектуальном поле мы не найдём, но не потому, что тут ничего нет, а в силу других обстоятельств.

Разумеется, нам могут возразить в том смысле, что многие люди способны и в реальности демонстрируют попытку понять другого человека. В качестве примера обычно называется научная дискуссия, где противоположные стороны выдвигают свои аргументы, объясняют свою позицию и приводят доводы в пользу своего мнения, используя при этом логический аппарат. Всё это так. Но одновременно с этим мы должны понимать, что диспуты состоятельны лишь в том случае, если их участники согласны друг с другом по ряду существенных параметров. В этом отношении спорщики оказываются одинаковыми - не внешне, конечно, а на ментальном уровне - что возвращает нас к поставленной проблеме. Но вначале небольшая ремарка.

Почему-то принято считать, что учёные наиболее честны как с остальными, там и прежде всего с самими собой. В том, что это в лучшем случае, лесть, а то и довольно раздутое самовосхваление, не должно быть никаких сомнений. Проблема состоит в том, что они тоже являются людьми, а, значит, к ним применимы все те пять пунктов, которые были перечислены выше в связи с первым симптомом.

Существует масса примеров того, как жестоко могут заблуждаться, а то и открыто ошибаться представители науки. Со времён Т. Куна, К. Поппера, И. Лакатоса [7; 8; 9], а также их многочисленных последователей уже и так ясно, что учёное сообщество в лучшем случае является всего лишь одним из многих подобных социальных групп. Тот факт, что ныне оно обладает просто-таки монструозными властью и мощью, не должно запутывать суть дело. Церковь тоже когда-то была крайне могущественна, но это ничего не говорило о её правоте или её образцовом характере или о чём-то ещё. Как и всякие люди, учёные не застрахованы от неудач, более того, подвержены им даже в большей степени, чем все остальные хотя бы потому, что они пытаются понять мир, тогда как другие заняты чем-то ещё. Вследствие этого их и нельзя воспринимать как носителей света, какими бы положительными качествами они ни обладали. Но вернёмся обратно.

Существует вопрос о том, как древние египтяне построили свои величественные и во всех смыслах грандиозные пирамиды. Подавляющее большинство людей, интересующихся данной тематикой и склонных вообще каким-либо образом объяснять самим себе способность к возведению 
столь великих сооружений, приходят от него в недоумение. Проблема состоит в том, что, по всей видимости, у этого народа в далёком прошлом отсутствовали необходимые технологии, с помощью которых подобное было бы осуществимо. Но незадача на самом деле заключается в том, что мы думаем о них в рамках сегодняшнего дня. Да, мы имеем и знания, и технику, и многое другое для того, чтобы воплотить такие планы в жизнь, а египтяне, скорее всего, ничем из нашего арсенала не располагали. В конце концов, современные исследователи застревают именно на неспособности древних, но не на их возможностях.

Мы даже говорим об этих усыпальницах или проще могилах, что вообще нередко забывается, в таких выражениях, которые больше подходят для дня настоящего, высчитывая какие-то углы и объёмы каменных блоков, измеряя зазоры между ними, выводя затраты в виде человеко-часов на их возведение, представляя себе, как они шлифовали строительный материал, а также доставляли его в нужное место. Увы, но это лишний раз показывает, насколько мы укоренены в своём собственном времени, напрочь забывая о том, что сами египтяне жили иначе, а, значит и не смотрели на свои сооружения через призму нашего лексикона.

И помимо учёных то же самое относится ко всем людям. Имея некоторый запас знаний и представлений, мы склонны наделять тем же самым багажом и всех остальных, а если мы на что-то не способны, то маховик начинает вращаться в противоположную сторону, и появляются заявления о невозможности. В действительности человек замыкается на том, что ему доступно, и почти всегда и всюду игнорирует то, к чему он не то, чтобы не в состоянии приблизиться, но, скорее, просто вообразить.

Так, в частности, шлифовка каменных блоков для пирамид могла легко осуществляться в Ниле, а их поднятие на высоту уже давно не представляется особой загадкой. Несмотря на то, что и эти деяния египтян описываются и реконструируются так, будто они осуществляются в наши дни, всё же они оказываются возможными даже в наших терминах. Если, однако, мы несколько усилим свой аргумент, то получится, что сам этот народ полагал реализуемым и нужным совсем не то, что приписываем мы ему, а потому и вёл себя, и строил совсем не так, как это рассматриваем мы.

Приведём ещё одну иллюстрацию, хотя, сознаёмся, не слишком очевидную. Посмотрим на мир глазами вирусолога. Он везде будет видеть тех созданий, которых он изучает, но главным окажется следующее. Он перенесёт представления об этих живых существах на те явления и предметы, которые не могут быть объяснены именно в таком ключе. Угол зрения крайне важен. Инженер отыщет конструкции, химик - реакции, физик - взаимодействия тел и сил.

Таким образом, проблема состоит даже не в том, что мы просто имеем некоторый набор воззрений, но в том, что, по большому счёту, считаем его единственно верным. Наши взгляды во многом объясняют нас, что делает нас уязвимыми к бесчисленным ошибкам постижения и интерпретации действительности.

И последний, третий симптом. Как поступить человеку, которому необходима трактовка некоторого явления, совершенно не вписывающегося в рамки его знаний? На этот вопрос существует несколько ответов. Первый - он попытается вникнуть в проблему поглубже, рассмотрит незнакомые ему материалы, оценит различные точки зрения и лишь затем даст какое-то объяснение. Такой подход в повседневном языке обозначается, как научный, и нам нет нужды изобретать какой-то другой термин.

Второй. Человек выдвинет интерпретацию в духе тех знаний и позиций, которые он уже и так занимает. Скажем, инженер станет говорить о сердце, как о приборе - насосе - просто потому, что с механизмами он сталкивался, а с живой материей нет, и у него отсутствует опыт обращения с последней. Сразу же подчеркнём, что это доминирующий среди большинства людей подход к объяснению незнакомой реальности. Стоит хотя бы упомянуть названия животных, многие из которых получили свои имена по аналогии с уже изученными или хотя бы просто виденными (слон - морской слон).

И третий ответ. Человек, либо не найдя релевантной информации, либо сославшись на собственное бессилие, прибегнет к помощи чего-либо сверхъестественного. В таком случае появятся слова и значения, доказать действительное существование которых почти невозможно. Конечно, наиболее ярким примером служит «Бог», но мы всё же вернёмся к иллюстрации с пирамидами.

Используя третий вариант, начинают заводить разговоры о том, что египтяне контактировали с инопланетянами, которые и поспособствовали возведению данных сооружений. Помимо того, что это, мягко говоря, никак не доказано, не совсем понятно, почему пришельцы посетили этот народ, а не другие, в то время, а не до или после, да и вообще не совсем ясно, зачем им понадобилось, чтобы кто-то здесь, на Земле построил пирамиды.

Интересно то, что человеческий разум в последнем случае придумывает самого себя для 


\section{Психология и психотехника 3(90) • 2016}

объяснения самого же себя. Инопланетяне - это, по сути, мы сами - они даже изображаются очень похожими на нас - обладающие нужными для интерпретации пирамид технологиями, ещё более конкретно нашими собственными, но порой и экстраполированными в будущее. Т.е. круг не разрывается, но ещё сильнее затягивается, и ментальная ловушка захлопывается. А египтяне получают экскаваторы, подъёмные краны, бетономешалки и многое другое. Ну, или звёздные суда и лебёдки. В этом смысле крайне показательны любые эзотерические учения. Они стремятся очеловечить то, что постичь не в состоянии, и в итоге не уходят дальше того, с чего, собственно, и начинали.

На самом деле данные три варианта ответа почти идентичны, хотя, на первый взгляд, так и не кажется. Во всех случаях человек не выходит за пределы того, что он знает и каким образом он размышляет о реальности. И если с двумя последними альтернативами всё, более или менее, понятно, то первый нуждается в дополнительном разъяснении.

Несмотря на кажущуюся новизну данного подхода, он, однако, редко выходит за собственные границы. Дело состоит в том, что всякое вновь полученное знание обычно располагается в уже имеющемся и вынуждено с ним как-то взаимодействовать. Разумеется, может случиться так, что пришелец заменит собой предшественника, но подобное случается редко. И даже при таком раскладе мы не просто получаем некие до того нам неизвестные данные, а всегда структурируем их. Например, человек, верящий в Бога, осведомляется об эволюции, но при этом продолжает считать, что люди всё-таки созданы Творцом или, по крайней мере, полагает, что сама она направляется последним.

Как бы ни хотелось учёным, но они столь же подвержены некоторого, на самом деле ничуть не меньшему, рода догматизму, что и люди далёкие от науки. В конце концов, трудно, если вообще возможно, уйти от того факта, что любое знание должно быть структурировано и вписано в систему, какой бы последняя ни оказалась. И данное обстоятельство усугубляется тем, что, как правило, дополнительные сведения не попадают в пустоту, но почти неизбежно оказываются чьим-либо соседями, т.е. располагаются рядом с уже существующими. В этом пункте все озвученные нами альтернативы сходятся, по сути, демонстрируя разновидности одного и того же подхода.

Помимо прочего, как показывает К. Поппер, наука, да и вообще всякая эпистемологическая деятельность, движется не в каком-то строго очер- ченном ею или кем-то ещё направлении, но почти исключительно методом проб и ошибок, вдобавок ко всему ещё и имея заранее определённые представления о том, что следует искать, а чего, соответственно, избегать, потому что иначе познание просто невозможно осуществить. Одними опытами и экспериментами сыт не будешь, тем более что и во времени, и в средствах мы все очень сильно ограничены, а это значит, что найдём мы почти исключительно только то, что и намеревались отыскать, тем самым ещё больше сужая собственный кругозор.

Таким образом, должно быть понятно, что синдром Электроника состоит из трёх симптомов, но мы ещё должны выяснить, взаимодействуют ли они друг с другом. Как можно было увидеть, первые два со всей очевидностью доказывают это. Наличие представлений о мире с необходимостью влечёт за собой мнение, согласно которому они являются единственно верными или, по крайней мере, крайне редко подпадают под критику, что между прочим, столь же нечасто вредит им. Сомнение само по себе способно выступать в качестве системного свойства некоторой совокупности воззрений, а потому отсекает возможность использования себя в роли ниспровергателя уже принятых и увековеченных ценностей.

Третий симптом просто нужно рассмотреть в ином ракурсе. Когда мы говорили о пирамидах, мы уже отчасти показали, как он взаимодействует с первыми двумя. Надо снова повторить, что объяснения в духе инопланетян на самом деле апеллируют не к чему-то внеземному, но, напротив, к тому, о чём и так уже давно известно. И то же самое в равной степени относится к эзотерике, религии и много чему ещё, включая и науку. В действительности нам нет необходимости приводить именно такие иллюстрации, но они просто наиболее показательны.

Инопланетяне в случае с пирамидами - это естественный заменитель нас самих. Если мы считаем, а нет особых резонов в пользу какого-либо сомнения, что египтяне явно не обладали нашими технологиями, то мы просто переносим себя в прошлое, но в виде каких-то иных существ, и паззлы автоматически складываются в более или менее сносную картину. При этом появляется стойкое желание отвергать альтернативные объяснения, а также подтверждать собственную правоту якобы имеющимися соответствиями и параллелями между наличными знаниями. Так, скажем, находятся свидетельства о каких-то значимых корреляциях между высотой этих сооружений и расстоянием до Солнца, или любые иные. 


\section{Потенциал интеллекта}

Мы просто не желаем знать, за исключением, наверное, историков и более узких специалистов египтологов, как жил этот народ по-настоящему, а не в соответствии с нашими весьма проблематичными реконструкциями их бытия. Если бы мы выяснили больше, нам было бы проще отыскать в их арсенале такие средства, которые бы и позволили им возводить столь удивительные для нас сооружения. Так мало кто поступает потому, что гораздо удобнее и легче думать о пирамидах в уже привычных категориях. И то же самое касается вообще всего спектра наших знаний о мире.

Однако вернёмся к самому Электронику. Робот, особенно такой совершенный, надо полагать, был способен, как это выяснилось позже, решать задачи Сыроежкина в том числе и на его уровне, но он не стал. Разумеется, можно сказать о том, что использование интегралов проще, чем умножения и деления, тем более для усвоивших первые, но в том-то и заключается проблема. Электроник применяет аппарат, не только доступный ему - иначе как объяснить его откровенный «провал»? - но и удобный для него. У него тоже есть привычки, в том числе и мыслительные, за рамки которых, при всех его достоинствах, он выйти не в состоянии. Вообще стоит заметить, что он идеален чуть ли не во всём, что только подчёркивает его человеческий характер. Так боги Древней Греции были больше людьми, чем те, кто их выдумал, являясь квинтэссенцией своих создателей.

Поэтому можно заявлять о том, что три симптома тесно связаны между собой, и при обнаружении одного из них должно быть понятно, что где-то кроются и два остальных. Однако, как нам вредит этот синдром и в чём он проявляется?

Существует такая дисциплина, как инженерная защита окружающей среды. Она предполагает использование технических средств с тем, чтобы решать экологические проблемы современности. Может показаться благом, что она вообще имеет место быть, но тут присутствует и своеобразный порочный круг. Огромная часть задач, взваленных на это направление мысли, на самом деле берёт своё начало именно в инженерной деятельности человека. Подобное пытаются вылечить подобным, прямо как в гомеопатии. Однако оставим этот научный предмет и обратимся к более нейтральному примеру. Многие люди знают, что похмелье снимается с помощью алкоголя. И, по крайней мере, отчасти это верно, но что в действительности происходит?

Человек, страдающий от абстиненции, разумеется, может выпить снова, но таким образом он опять опьянеет, что лишь отодвинет проблему на более отдалённое время, а то и сильно усугубит её. Во многом мы все похожи на того, кто накануне перебрал и теперь испытывает все прелести своего нынешнего состояния. При этом большинство поступит ровно также, как и этот персонаж, т.е. использует свой мыслительный аппарат, который и завёл его в данное положение, точно также, как делал это раньше.

Конечно, можно оценивать такую ситуацию двояко. В конечном счёте, Электроник всё же решил задачу Сыроежкина - просто сделал это не совсем адекватно обстоятельствам. Сам результат не поддаётся никакому сомнению. Однако так ли это? Мы все проживаем в определённом контексте, и он не является обычным и легко поддающимся устранению фоном, но неотъемлемой частью нашего бытия. В советском фильме шестиклассник должен был найти ответ в рамках некоторой структуры, т.е. в пределах собственного знания, в противном случае выполненное задание нерелевантно, что и демонстрируется ходом сюжета. Сыроежкина наказывают не вследствие лжи, но из-за того, что тот применяет неверные практики. Это напоминает расхождение между двумя типами логики [10]. Нельзя везде использовать одни и те же, пусть и работающие, подходы. В этом смысле очень существенное значение играет вопрос «как?». Не стоит полагать, что «так» в одном месте будет столь же оправданным «так» и в другом, а то и приемлемым в принципе.

Естественно, мы можем представить себе ситуации, в рамках которых востребованы универсальные типы решений. Однако проблема в том и состоит, что вряд ли где-либо и когда-либо подобная универсальность была бы в состоянии себя проявить. Абсолютной логикой обладает столь же абсолютный мыслитель, для всех остальных зарезервированы места рангом пониже. Кроме того, вызывает серьёзные сомнения само предположение о наличие такого метода, который бы подходил ко всем дверям. Загвоздка состоит в том, что люди имеют ограниченный опыт, склонны к субъективности, а также подвергаются влиянию своего окружения, что и делает их лёгкой жертвой обсуждаемого синдрома. И данный текст, скорее всего, демонстрирует его в той же степени, что и любой иной.

Синдром Электроника, таким образом, олицетворяет человеческую склонность использовать уже имеющиеся механизмы познания и объяснения имманентные той обстановке, которая требует от людей не только и даже не столько верного ответа, сколько соответствия наличным условиям. Самое интересное состоит в том, что мы нередко всё же 


\section{Психология и психотехника 3(90) • 2016}

поступаем правильно, принимая во внимание специфику обстоятельств, а, значит, и отвергая их, но так происходит нечасто. Поэтому можно с уверенностью говорить о том, что такой синдром есть неотъемлемая черта всякого мыслящего и вынужденного находить решения индивида, просто потому, что у каждого с необходимостью имеется интеллектуальная структура, диктующая определённый взгляд на вещи, обусловленный рядом обстоятельств.

Такова логика вещей. Будучи общественными животными, мы вынуждены быть конформными не только в отношении правил поведения, но также и мышления и чувствования. Потому что нас учат не только как правильно себя вести, но и что думать и переживать. Сыроежкины должны решать задачи так, как это предписывается нормами, принятыми самой логикой преподавания в школе, т.е. использовать простейшие математические операции, а не интегралы. Применение последних влечёт за собой дисциплинарное наказание. Но то же самое можно сказать и обо всех нас. Тот факт, что мы что-то усвоили в процессе социализации, не только говорит о том, что мы знаем, но и то, о чём нам неизвестно, а также то, как именно мы будем смотреть на окружающую нас реальность. Синдром Электроника, таким образом, заключается в том, что мы применяем и выполняем те операции, которые не обязательно подходят для поставленной проблемы, но зато удовлетворяют тому, что от нас ожидают прочие члены нашей группы, которые обладают столь же зауженным мировоззрением, что и мы сами.

И последнее, между строк. Сыроежкин неправильно произносит слово «интеграл», которое ему подсказывает его одноклассник, выдавая своё незнание, а, значит, и то, что кто-то ему помог в решении задачи. Удивительно, хотя и вполне логично в свете того, что было сказано выше, то, что последний, даже будучи в курсе такого способа вычисления, тем не менее, повёл себя, как и остальные. А в таком случае он даже хуже главного персонажа, потому что для него конформность оказывается выше истины. Но мы, скорее, Сыроежкины, чем подобные всезнайки.

\section{Список литературы:}

1. Джером Д.К. Трое в лодке, не считая собаки. М.: АСТ, 2006. 288 с.

2. URL: http://dic.academic.ru/dic.nsf/enc_medicine/28878/Синдром.

3. Morris I. Foragers, Farmers, and Fossil Fuels: How Human Values Evolve. Princeton University Press, 2015. 400 p.

4. Darwin C. The origin of species. Bantam Classics, 1999. 512 p.

5. Kahneman D. Thinking fast and slow // Farrar, Straus and Giroux, 2011. P. 65.

6. Якобони М. Отражаясь в людях. Почему мы понимаем друг друга. М.: Юнайтед Пресс, 2011. 366 с.

7. Кун Т. Структура научных революций. М.: АСТ, 2015. 320 с.

8. Поппер К.Р. Предположения и опровержения. Рост научного знания. М.: АСТ, 2008. 640 с.

9. Лакатос И. Избранные произведения по философии и методологии науки. М.: Академический Проект, 2008.480 с.

10. Борзых С.В. Ситуативная и нормативная логики // Наука в различных измерениях: сборник научных трудов II Междунар. научно-практ. конф., посвящ. памяти докт. филос. наук, проф. Г.Ф. Миронова, г. Ульяновск, 17-18 мая 2010 г. / Под ред. Т.Н. Брысиной. Ульяновск, 2010. С. 89.

11. Розин В.М. К уточнению понятия «наука» // Философия и культура. 2010. № 10. С. 29-38.

12. Розин В.М. Правдоподобные конспирологические теории (дискурсивный анализ) // Политика и общество. 2016. № 3. С. 301-310. DOI: 10.7256/1812-8696.2016.3.18273.

13. Гуревич П.С. Кто он - человек? // Философия и культура. 2015. № 6. C. 797-801. DOI: 10.7256/1999-2793.2015.6.15598.

\section{References (transliterated):}

1. Dzherom D.K. Troe v lodke, ne schitaya sobaki. M.: AST, 2006. $288 \mathrm{s.}$

2. URL: http://dic.academic.ru/dic.nsf/enc_medicine/28878/Sindrom.

3. Morris I. Foragers, Farmers, and Fossil Fuels: How Human Values Evolve. Princeton University Press, 2015.400 p.

4. Darwin C. The origin of species. Bantam Classics, 1999. $512 \mathrm{p}$.

5. Kahneman D. Thinking fast and slow // Farrar, Straus and Giroux, 2011. P. 65.

6. Yakoboni M. Otrazhayas' v lyudyakh. Pochemu my ponimaem drug druga. M.: Yunaited Press, 2011. 366 s.

7. Kun T. Struktura nauchnykh revolyutsii. M.: AST, 2015. 320 s.

8. Popper K.R. Predpolozheniya i oproverzheniya. Rost nauchnogo znaniya. M.: AST, 2008. $640 \mathrm{~s}$.

9. Lakatos I. Izbrannye proizvedeniya po filosofii i metodologii nauki. M.: Akademicheskii Proekt, 2008. $480 \mathrm{~s}$.

10. Borzykh S.V. Situativnaya i normativnaya logiki // Nauka v razlichnykh izmereniyakh: sbornik nachnykh trudov II Mezhdunar. nauchno-prakt. konf., posvyashch. pamyati dokt. filos. nauk, prof. G.F. Mironova, g. Ul'yanovsk, 17-18 maya 2010 g. / Pod red. T.N. Brysinoi. Ul'yanovsk, 2010. S. 89.

11. Rozin V.M. K utochneniyu ponyatiya «nauka» // Filosofiya i kul'tura. 2010. № 10. S. 29-38.

12. Rozin V.M. Pravdopodobnye konspirologicheskie teorii (diskursivnyi analiz) // Politika i obshchestvo. 2016. № 3. S. 301-310. DOI: 10.7256/1812-8696.2016.3.18273.

13. Gurevich P.S. Kto on - chelovek? // Filosofiya i kul'tura. 2015. № 6. S. 797-801. DOI: 10.7256/1999-2793.2015.6.15598. 